\title{
LEGISLAÇÃO BRASILEIRA APLICADA À PRODUÇÃO DO INSUMO FARMACÊUTICO ATIVO HEPARINA
}

\section{BRAZILIAN LEGISLATION APPLIED TO THE PRODUCTION OF PHARMACEUTICAL ACTIVE INPUT HEPARINA}

\author{
Eva Elisângela Borges da SILVA ${ }^{1}$; Valtemir Borges da SILVA², Gabriela Bonfanti \\ AZOLIN ${ }^{1}$; Regis Augusto Norbert DEUSCHLE'; Viviane Cecília Kessler Nunes \\ DEUSCHLE $^{3^{*}}$
}

1 - Curso de Farmácia, Centro de Ciências da Saúde e Agrárias - CCSA, Universidade de Cruz Alta, Cruz Alta, Rio Grande do Sul, Brasil. UNICRUZ;

2 - Engenheiro Químico; Especialista em Vigilância e Regulação Sanitária; Coordenação de Inspeção de Insumos Farmacêuticos - COINS. Agência Nacional de Vigilância Sanitária - ANVISA. Brasília, Distrito Federal, Brasil.

3 - Autor correspondente, Grupo de Pesquisa em Atenção Integral à Saúde (GPAIS), Centro de Ciências da Saúde, Curso de Farmácia, Universidade de Cruz Alta, Cruz Alta, Rio Grande do Sul, Brasil.

Autor para correspondência: E-mail: vdeuschle@unicruz.edu.br

\section{RESUMO:}

O controle sanitário dos medicamentos é realizado através das legislações vigentes no Brasil e visa monitorar a qualidade dos mesmos e se dá, em todas as relações da cadeia de medicamentos, desde a descoberta de uma nova molécula até a sua comercialização. A heparina é utilizada há mais de 50 anos na terapêutica como agente anticoagulante e antitrombótico e está presente em uma grande variedade de tecidos animais, sendo obtida principalmente destas fontes. Neste contexto, é objetivo desse trabalho, realizar uma revisão da literatura abordando a legislação necessária para a produção do insumo farmacêutico heparina pela indústria nacional. Esse trabalho trata-se de uma revisão descritiva qualitativa da literatura a respeito das principais legislações brasileiras aplicadas a fabricação do insumo farmacêutico heparina. Observa-se que para a produção do insumo farmacêutico heparina, a indústria deve seguir os requisitos mínimos de qualidade e obedecer as Boas Práticas de Fabricação, de acordo com a RDC 69/2014. Com a realização desta pesquisa foi possível verificar a importância da aplicação da legislação, bem como de seu cumprimento para que os insumos farmacêuticos produzidos no Brasil apresentem qualidade, segurança e eficácia de forma a preservar a saúde do usuário.

Palavras chave: Legislação como Assunto. Boas práticas de fabricação. Insumos farmacêuticos.

\section{ABSTRACT:}

The sanitary control of medicinal products is carried out through existing laws in Brazil and aims to monitor the quality of the same and, in all the medicines chain relations, since the discovery of a new molecule to its marketing. Heparin is used for more than 50 years in therapy as an anticoagulant and antithrombotic and is present in a wide variety of animal 
tissues, being obtained primarily from these sources. In this context, is aim of this work, conduct a review of the literature addressing the legislation needed for the production of pharmaceutical industry heparin national input. This work deals with a descriptive qualitative systematic review of the literature regarding the main Brazilian legislation applied to the manufacture of pharmaceutical heparin input. It is observed that for the production of pharmaceutical industry Heparin input must follow the minimum quality requirements and comply with the good manufacturing practices, according to the DRC 69/2014. With the accomplishment of this research it was possible to verify the importance of the application of the legislation, as well as its compliance so that the pharmaceutical inputs produced in Brazil present quality, safety and efficacy and to preserve the health of the user.

Keywords: Legislation as Topic. Good manufacturing practices. Pharmaceutical Raw Material.

\section{INTRODUÇÃO}

O controle sanitário dos medicamentos é realizado através das legislações vigentes no Brasil que visa monitorar a qualidade dos mesmos e se dá, em todas as relações da cadeia de medicamentos, desde a descoberta de uma nova molécula para uso humano, produção e distribuição até a elaboração de normas para o registro de medicamento e concessão do Estado para a sua comercialização se comprovadas qualidade, segurança e eficácia de determinado medicamento em determinada dose para fins específicos (PAULA et al., 2009; MASTROIANNI; LUCCHETTA, 2011).

De acordo com RDC 29/2010 da Agência Nacional de Vigilância Sanitária (ANVISA), Insumo farmacêutico ativo (IFA) é qualquer substância introduzida na formulação de uma forma farmacêutica que, quando administrada em um paciente, atua como ingrediente ativo. Tais substâncias podem exercer atividade farmacológica ou outro efeito direto no diagnóstico, cura, tratamento ou prevenção de uma doença, podendo ainda afetar a estrutura e funcionamento do organismo humano (BRASIL, 2010).

Os insumos farmacêuticos (IF) representam o início da cadeia produtiva da indústria farmacêutica. Com a finalidade de assegurar a qualidade na produção de medicamentos, a ANVISA é responsável pela autorização de funcionamento das empresas e pelo controle sanitário dos insumos farmacêuticos, mediante a realização de inspeções sanitárias e elaboração de normas (ANVISA, 2006; GONÇALVES, 2006; BRASIL, 2015).

A maioria dos IFAs derivam da síntese química, que resulta na obtenção do fármaco e envolve a transformação de compostos químicos, através da alteração de suas estruturas moleculares até a obtenção do princípio ativo desejado (MITIDIERI, 2015).

A heparina foi descoberta por um aluno do segundo ano de medicina da Universidade Johns Hopkins Hospital em 1916, quando procurava extrair substâncias 
tromboplásticas de vários tecidos, então acabou encontrando uma substância com potente atividade anticoagulante (RANG et al., 2011). Sua estrutura química (Figura 1) foi elucidada em 1936 e foi descrita como um éster polissulfúrico de um polissacarídeo composto por glucosamina e ácido urônico (MULLOY et al., 2016). É utilizada há mais de 50 anos na terapêutica como agente anticoagulante e antitrombótico e está presente em uma grande variedade de tecidos animais, sendo obtida principalmente destas fontes, fazendo parte da lista de medicamentos essenciais da Organização Mundial da Saúde (MELLO et al., 2008; BARROWCLIFFE, 2012). Apesar de outros anticoagulantes serem disponíveis, como a warfarina e outros inibidores diretos de trombina e fator Xa $(\mathrm{FXa})$, a heparina não fracionada continua sendo o medicamento de escolha, principalmente em intervenções cirúrgicas (MESSMORE et al., 2004; MELLO et al., 2008; RANG et al., 2011; BARROWCLIFFE, 2012).

Grande parte da heparina utilizada é isolada da mucosa intestinal de suínos, e em menor quantidade do tecido pulmonar bovino (AQUINO et al., 2010; TOVAR et al., 2013; SANTOS et al., 2014). O processo de isolamento envolve hidrólise da mucosa seguida pela extração de heparina, utilizando enzimas proteolíticas sob aquecimento, seguida pela adsorção dos poliânions sulfatados para uma resina de troca iônica, sendo estes em seguida recuperados. No decorrer do isolamento, as cadeias glicosaminoglicanas tornamse levemente degradadas, produzindo mistura heterogênea de fragmentos com diferentes massas moleculares e características biológicas. Além dos materiais citados, outros são utilizados com a finalidade de estabilizar o meio de reação, podendo, ao final do processo, aparecer no produto final como contaminantes (LONGHI; LAKS; KALIL, 2001; LIVERANI; MASCELLANI; SPELTA, 2009; WALENGA; LYMAN, 2013).

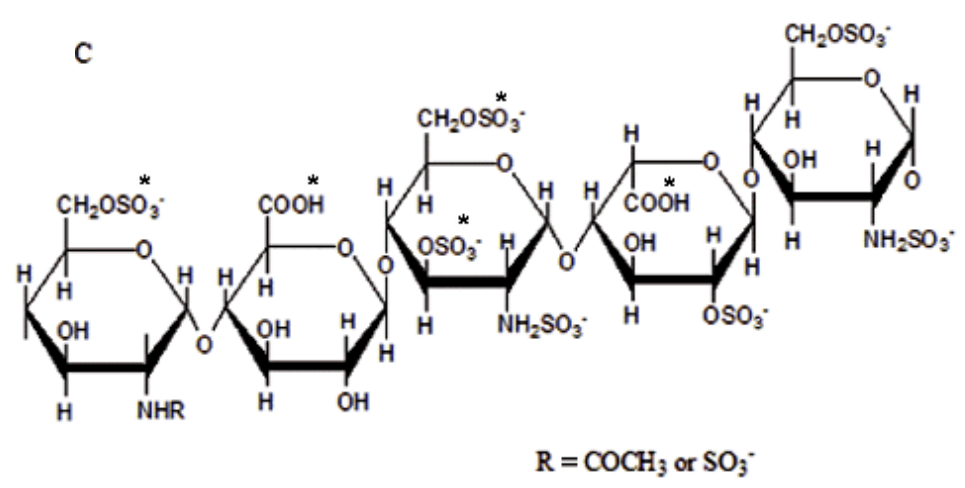

Figura 1 - Estrutura química da heparina (Fonte: Adaptado de MULLOY, 2016.9)

Outro ponto relevante na produção de heparina está relacionado ao rendimento do 
processo e localização das unidades produtoras. O conteúdo de mucosa no meio aquoso é muito pequeno e, em consequência, grandes quantidades de tecido precisam ser processadas. A localização das empresas produtoras, geralmente distantes dos locais de criação ou abate dos animais, são outro fator complicador na produção, uma vez que a mucosa coletada deve ser transportada por grandes distâncias, algumas vezes em condições pouco adequadas, ocasionando a produção de um material de baixa qualidade para o futuro processamento (FILHO, 2009). Ainda, os animais dos quais a heparina é derivada devem cumprir os requisitos sanitários para a espécie em questão e o processo de produção deve garantir a retirada ou inativação de agentes infecciosos (BRASIL, 2010; GUERRINI et al., 2008).

A ação anticoagulante da heparina está relacionada aos grupamentos químicos sulfatados que decorrem de grupos aniônicos que interagem com os fatores de coagulação (DELUCIA et al., 2007; GUERRINI et al., 2008; AQUINO et al., 2010). O mecanismo de ação da heparina se dá através da inibição da trombina e dos outros fatores da coagulação ativados como XIla, IXa e Xa. Para exercer a sua função anticoagulante, a mesma requer um co-fator plasmático, a antitrombina III. A heparina fixa-se à antitrombina III, induzindo uma modificação conformacional dessa molécula, que expõe o sítio ativo acessível à trombina e às outras proteases resultantes da ativação dos fatores da coagulação (DELUCIA et al., 2007; MELLO et al., 2008; MASUKO; LINHARDT, 2012; MULLOY et al., 2016).

Neste contexto, é objetivo desse trabalho, realizar uma revisão sistemática da literatura abordando a legislação necessária para a produção do insumo farmacêutico heparina pela indústria brasileira e apontar os principais requisitos exigidos pela legislação vigente.

\section{METODOLOGIA}

Esse trabalho constitui-se de uma revisão descritiva qualitativa da literatura a respeito das principais legislações brasileiras aplicadas à fabricação do insumo farmacêutico heparina. Trata-se de uma metodologia proposta para identificar os estudos sobre um tema em questão, aplicando métodos explícitos e sistematizados de busca com o objetivo de avaliar a qualidade e validade desses estudos (LOPES; FRACOLLI, 2008).

Para isso foram utilizadas as seguintes bases de dados: Scielo, Google acadêmico, Birene, Pubmed, Lilax e também no portal da Agência Nacional de Vigilância Sanitária (ANVISA). Os descritores utilizados na busca foram: insumo farmacêutico, insumo farmacêutico ativo, legislação brasileira relacionada à insumos farmacêuticos, heparina, 
legislação relacionada à heparina, legislação relacionado aos insumos biológicos, legislação farmacêutica, extração de insumos animais.

No estudo foram incluídas todas as Leis, Resoluções e Portarias referentes ao registro, produção, controle e garantia da qualidade de insumos farmacêuticos e a produção de heparina no Brasil além de artigos científicos relacionados ao tema, independente do período de publicação. Foram excluídos os artigos e legislações que não estavam estritamente relacionados ao tema e aos descritores utilizados na busca. Todos os demais foram incluídos na pesquisa

\section{RESULTADOS E DISCUSSÃO}

O setor farmoquímico tem sua importância destacada na cadeia farmacêutica por tratar-se daquele que fornece a principal matéria-prima para a produção de medicamentos: o fármaco ou princípio ativo, também denominado Insumo Farmacêutico Ativo (IFA), ou seja, substância presente na formulação farmacêutica responsável por seu efeito terapêutico (ARREPIA; COSTA; TABAK, 2015).

De acordo com a RDC № 39/2013 (BRASIL, 2013), Insumo Farmacêutico (IF) é a definição dada a "qualquer droga ou matéria-prima aditiva ou complementar de qualquer natureza, destinada a emprego em medicamentos, quando for o caso, e seus recipientes".

A Figura 2 mostra o fluxograma demonstrativo dos processos que o IFA pode passar até chegar à indústria farmacêutica e ser transformado em medicamento.

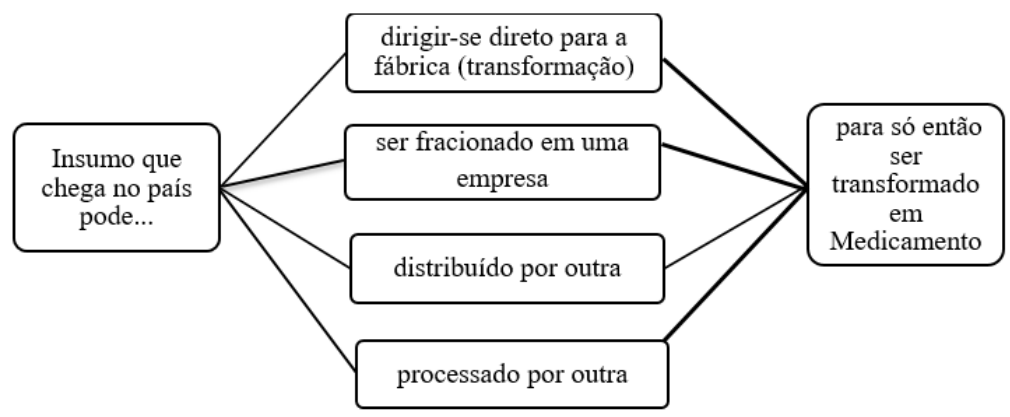

Figura 2 - fluxograma demonstrativo dos processos que o IFA pode passar até chegar à indústria farmacêutica

O medicamento obtido após o processo produtivo para ser comercializado, deve atender aos quesitos mínimos de qualidade especificados nos compêndios oficiais reconhecidos 
pela ANVISA. A qualidade do produto final é assegurada através da gestão da produção que depende diretamente dos insumos (PONTES et al., 2009).

Atualmente, o Brasil importa aproximadamente $90 \%$ a $95 \%$ dos fármacos utilizados pela indústria de medicamentos, o que o deixa numa dependência muito grande do mercado externo e coloca a indústria farmoquímica brasileira numa situação de quase inexistência já que o país depende da importação de IFAs (BRASIL, 2013).

Os principais IFAs, por classe terapêutica, produzidos no país são os analgésicos, anestésicos, ansiolítico-relaxantes musculares, antidepressivos-antimaníacos e antivirais. Para alguns IFAs, existe simultaneidade de muitos fabricantes, podendo ocorrer concorrência direta entre os mesmos, ou excepcionalmente, a formação de um consórcio de empresas privadas para fornecimento de um IFA à um laboratório farmacêutico oficial. Outro dado importante a ser destacado é que o setor farmoquímico está mais concentrado na região Sudeste do país (BRASIL, 2013).

O controle sanitário dos medicamentos, realizado através das legislações vigentes no Brasil, visa monitorar a qualidade dos mesmos e se dá, em todas as relações da cadeia de medicamentos, desde a descoberta de uma nova molécula para uso humano, produção e distribuição até a elaboração de normas para o registro de medicamento e concessão do Estado para a sua comercialização, se comprovadas qualidade, segurança e eficácia de determinado medicamento em determinada dose para fins específicos. Irregularidade no controle de qualquer uma das etapas desta cadeia pode resultar na comercialização de produtos de qualidade, segurança ou eficácia dúbia (PAULA et al., 2009).

O controle de qualidade dos IFAs passou a ser realizado a partir Lei ํㅜ 5.991/73 (BRASIL, 1973) que é regulamentada pelo Decreto no 74.170/74 (BRASIL, 1974), ambos da ANVISA, e que dispõe sobre o controle sanitário do comércio de drogas, medicamentos, insumos farmacêuticos e correlatos. No entanto, no decorrer do tempo e conforme as necessidades e modificações sofridas nos processos acabaram surgindo novas regulamentações, decretos e instruções normativas a fim contemplar todas as exigências impostas ao setor.

Atualmente, a RDC no 69/14 (ANVISA) regulamenta esse processo e é descrita no Art. $3^{\circ}$ da mesma como sendo a resolução que "estabelece os procedimentos e as práticas que o fabricante deve aplicar para assegurar que as instalações, métodos, processos, sistemas e controles usados para a fabricação de IFA sejam adequados, de modo a garantir a qualidade e permitir seu uso na elaboração de produtos farmacêuticos" (MASTROIANNI; LUCCHETTA, 2011). Entre essas determinações estão: a estrutura que o laboratório de 
controle de qualidade deve possuir, a validação dos processos, estudos de estabilidade, controle durante as etapas de desenvolvimento e validação de processos produtivos, especificação da matéria-prima, entre outros. A falta de especificações mais criteriosas pode levar à aquisição de insumos que podem gerar sérios problemas na produção e comprometimento da qualidade do produto (BRASIL, 2014).

As legislações aplicadas ao registro e controle de qualidade de IFAs utilizados no Brasil desde 1973 encontram-se sumarizadas na Figura 3.

Figura 3 - Linha do tempo sobre as legislações Brasileiras aplicadas ao registro e controle de qualidade de IFAs no Brasil
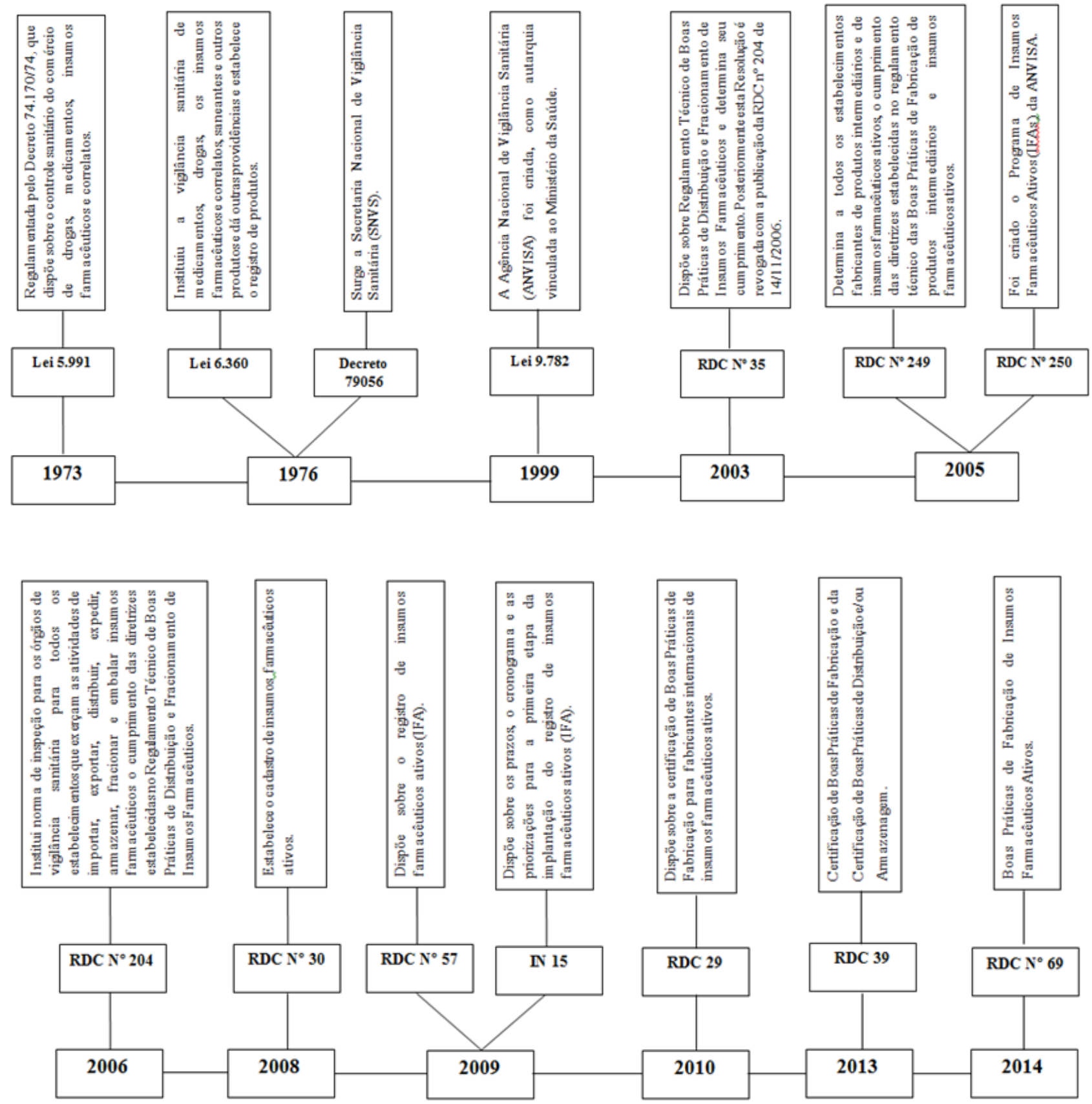
Conforme descrito no Anexo I da RDC 69/2014 (BRASIL, 2014) o processo de corte, mistura e processamentos iniciais (extração e purificação inicial) não estão incluídos no escopo dessa RDC. A mesma determina o cumprimento das diretrizes estabelecidas no Regulamento Técnico das Boas Práticas de Fabricação de produtos intermediários e IFAs a todos os estabelecimentos fabricantes dos mesmos.

A heparina pertence a um grupo de fármacos de suma importância na medicina, pois tem função anticoagulante, utilizados na prevenção e tratamento de tromboses e embolias arteriais e venosas. É obtida principalmente a partir da mucosa intestinal bovina e suína (LONGHI; LAKS; KALIL, 2001; DELUCIA et al., 2007; MASUKO; LINHARDT, 2012; WALENGA; LYMAN, 2013).

A heparina é encontrada em duas formas de apresentações clínicas: as Heparinas Não-Fracionadas (HNF), polissacarídeos que durante o isolamento dos tecidos animais tornam-se levemente degradados produzindo uma mistura heterogênea de fragmentos com massa molecular entre 3.000 e 30.000 Daltons e as Heparinas de Baixo Peso Molecular (HBPM), obtidas através da despolimerização controlada da HNF, obtendo-se produtos com massas moleculares entre 4000 e 6000 Daltons (MAURO et al., 2004). As HBPM são formadas por fragmentos, que possuem as mesmas funções das HNF e são consideradas clinicamente mais seguras, tendo efeitos adversos minimizados (BONEU, 2000).

O processo de produção da heparina no Brasil segue as legislações vigentes no país como a RDC n 69/2014 que regulamenta as BPFs de IFA. Por pertencer a classe dos biomedicamentos que são medicamentos obtidos a partir de fluidos biológicos ou de tecidos de origem animal ou medicamentos obtidos por procedimentos biotecnológicos, também deve seguir a RDC nº 55/2010 que possui o objetivo de estabelecer os requisitos mínimos para o registro de produtos biológicos novos e produtos biológicos no país (MAURO et al., 2004; BRASIL, 2014).

Sendo assim, empresas que realizam as atividades de coleta corte e mistura e/ou processamentos iniciais não precisam ser avaliadas para fins de certificação de BPF e devem seguir a legislação imposta pelo Ministério da Agricultura (MA), responsável pela emissão do certificado sanitário do frigorífico. Entretanto, a empresa deve garantir que seu material de partida atenda as especificações, já que a qualidade de seu insumo depende desse material (BRASIL, 2010; BRASIL, 2014).

O processo de extração de heparina a partir da mucosa bovina e suína apresentase esquematizado na figura 4 do fluxograma abaixo. 


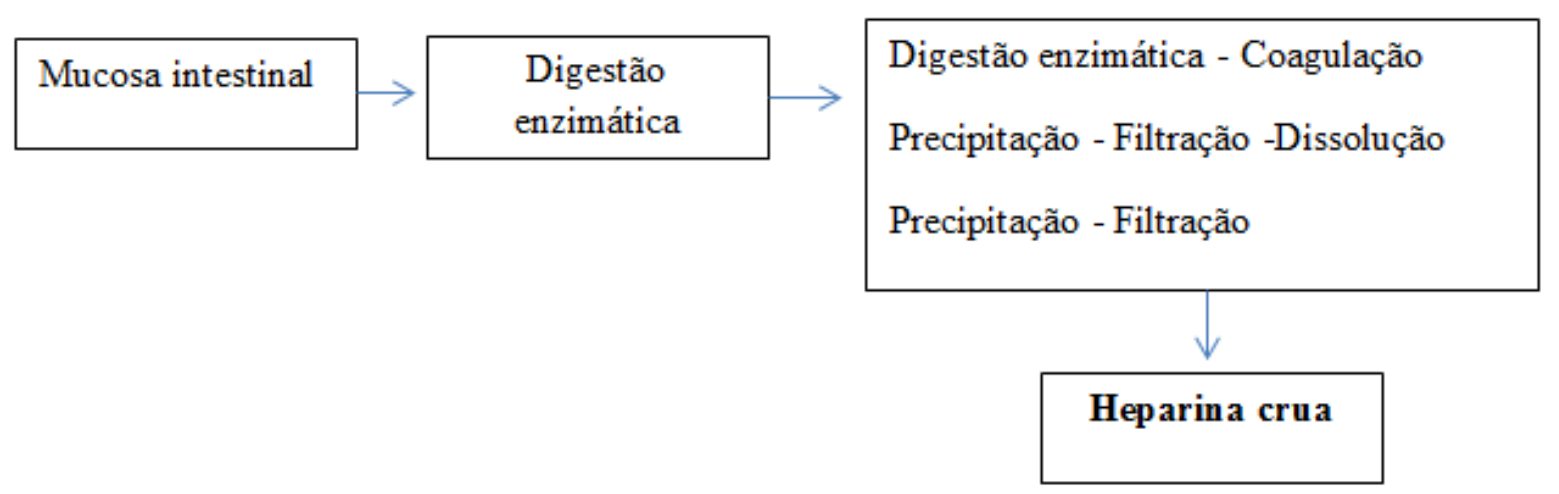

Figura 4 - Fluxograma de produção da heparina a partir da mucosa bovina ou suína

Antes da obtenção do material de partida, isto é, a heparina crua, a empresa deve ter controles ainda que não exigidos pela legislação. Estes controles são importantes para a garantia da qualidade do material obtido. Normalmente, como as empresas devem cumprir as BPF a partir do material de partida, estas optam por adotar as Boas Práticas anteriores a esse processo para garantir a qualidade do material. Portanto, as empresas não são obrigadas a cumprir as BPF antes do material de partida, mas são obrigadas a realizar o controle do processo como descrito no Art.4ํㅡ da RDC no 69/2014 em que mostra que o fabricante de insumos farmacêuticos ativos deve assegurar que estes sejam adequados para o uso pretendido e que estejam de acordo com os requisitos de qualidade e pureza (BRASIL, 2014).

Esses controles são definidos pela indústria, que determina quais são os pontos críticos, baseado nas particularidades de cada processo desenvolvido pela própria empresa. A legislação não destaca o que é crítico no processo, mas sim como devem ser feitos tais controles. A partir da definição do material de partida e inclusão deste no processo produtivo, a produção e o processo de extração do IFA deve seguir a RDC no 69/2014 integralmente (BRASIL, 2014).

O processo de produção do insumo heparina a partir da heparina crua está demonstrado esquematicamente no fluxograma representado na Figura 5.

Ainda, após a obtenção do material de partida, a legislação determina que sejam feitos controles de parâmetros durante os processos, conforme descrito no Art.6o da RDC no 69/2014 que determina que o fabricante deve apresentar evidências do cumprimento das BPFs, a partir da obtenção do material de partida (BRASIL, 2014). Alguns desses parâmetros estão exemplificados na Tabela 1. 
Tabela 1 - Parâmetros analisados durante o processo de purificação da Heparina Crua.

\section{Purificação da Heparina Crua}

\begin{tabular}{cc}
\hline Etapas do processo & Controles em processo \\
\hline Inativação viral & $\mathrm{pH}$ \\
Oxidação por permanganato de potássio & Temperatura \\
Oxidação por peróxido de hidrogênio & $\mathrm{pH}$ \\
Hidratação & ------ \\
\hline Filtração esterilizante & ----- \\
\hline Segunda filtração & $\mathrm{pH}$ \\
Precipitação & Temperatura \\
Desidratação alcoólica & Teor alcoólico \\
Secagem & Temperatura \\
Moagem & Tamanho de partícula \\
\hline
\end{tabular}

Fonte: Adaptado ANVISA

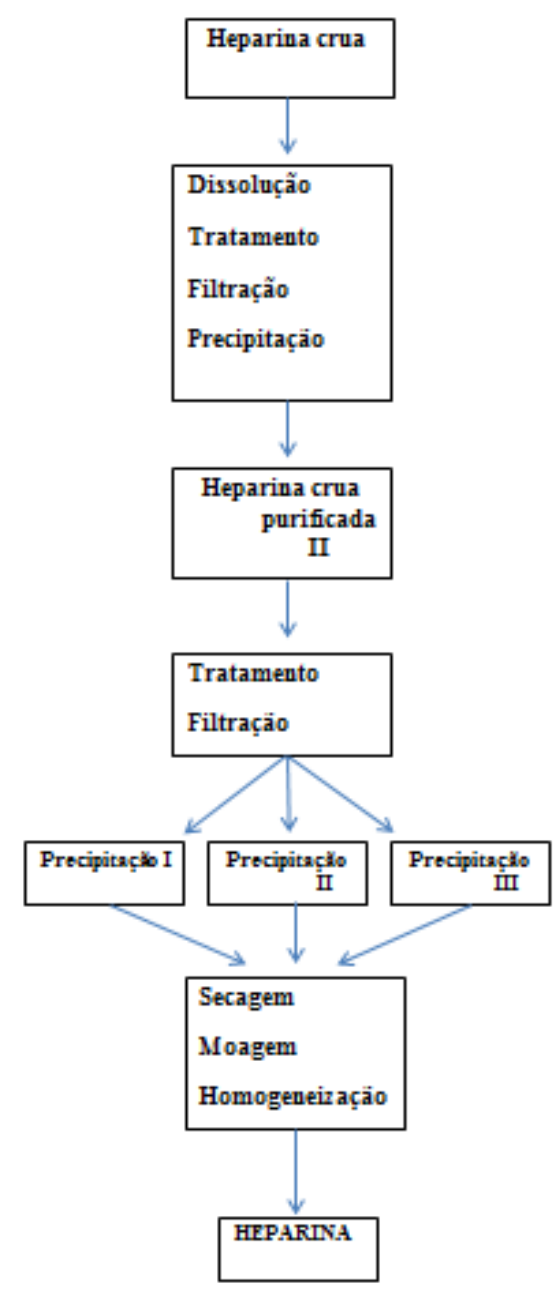

Figura 5 - Fluxograma de Produção de Heparina a partir da heparina crua 
De acordo com a RDC 69/2014, conforme descrito no Art. $3^{\circ}$, esta resolução estabelece os procedimentos e as práticas que o fabricante deve aplicar para assegurar que as instalações, métodos, processos, sistemas e controles usados para a fabricação de IFAs sejam adequados e que venham garantir a qualidade e permitir seu uso na elaboração de produtos farmacêuticos (BRASIL, 2014).

A seguir será relatado alguns dos pontos críticos de que trata a RDC № 69/2014, à produção dos IFAs no Brasil, no qual se enquadra a heparina (BRASIL, 2014).

No Capítulo II dessa resolução é relatado sobre o gerenciamento de qualidade e o Art. $7^{\circ}$ descreve de forma geral as responsabilidades da empresa na qual o fabricante deve estabelecer, documentar, implementar e manter um sistema eficaz para o gerenciamento da qualidade, que abrange a participação ativa da gerência e de todo o pessoal envolvido na fabricação. Neste mesmo tópico está exposta as responsabilidades deste setor, assim como a descrição de como deve ser realizada a revisão e a auto inspeção de qualidade.

Desta forma, como em qualquer estabelecimento relacionado à produção de insumos e medicamentos no Brasil, o que garante a qualidade dos mesmos é uma série de fatores que em conjunto irão assegurar a eficácia do produto final. Observa-se que a ANVISA, como um órgão regulamentador vinculado ao Ministério da Saúde, estabelece os requisitos mínimos para garantir a segurança e eficácia e prima pela saúde da população, evitando possíveis danos. Esse conjunto de normas e padrões envolve desde o recebimento do material de partida e qualificação dos fornecedores, passando pela gestão de pessoal envolvido no processo, através de treinamentos e capacitações contínuas até o controle documental de procedimentos e registros.

Outro ponto de extrema importância para o setor é em relação a qualidade da água utilizada na produção dos IFAs que deve ser monitorada e adequada para o uso pretendido conforme descrito no Art. $78^{\circ}$. Ainda no Art. $81^{\circ}$ é relatado que, caso a água usada no processo seja tratada pelo fabricante, o sistema de tratamento deve ser validado e monitorado.

Todos os processos necessitam ser registrados, rastreáveis e estar prontamente disponíveis para a ANVISA para fins de fiscalização, conforme descrito no Capítulo VI. Ainda nesse capítulo cita-se a necessidade de especificações de matérias-primas, intermediários, IFAs, materiais de embalagem e rotulagem. O Art. $115^{\circ}$ determina que as especificações, metodologias analíticas e critérios de aceitação devem ser estabelecidos e documentados, assim como a rota de síntese conforme descrito no Art. $118^{\circ}$ e Art. $119^{\circ}$, e que a mesma deve ser especificada. Também o comportamento estereoquímico das 
moléculas deve ser conhecido, assim como devem ser identificados os centros quirais da molécula e as diferenças farmacológicas entre os isômeros, quando aplicável.

No que se refere ao controle de materiais, o Art. $136^{\circ}$ estabelece que os mesmos devem ser recebidos, identificados, armazenados, colocados em quarentena, amostrados, manuseados, analisados conforme especificações estabelecidas e identificados quanto a sua situação conforme os procedimentos escritos. Todo material deve ser mantido em quarentena, imediatamente após o recebimento, até que seja determinada sua disposição pela unidade da qualidade como descrito no Art. $142^{\circ}$. Ainda neste capítulo é descrito sobre as condições de armazenamento adequado de forma a prevenir a degradação e a contaminação dos produtos, além de preservar a sua integridade e identidade. Os materiais não aprovados devem ser identificados, segregados e controlados de forma a impedir o seu uso.

O setor de controle de qualidade deve ser uma unidade independente da produção e os IFAs devem apresentar especificações adequadas de acordo com padrões de aceitação e ser consistentes com o processo de produção. Essas especificações devem incluir controle das impurezas e, caso o IFA tenha especificação para pureza microbiológica, os limites para contagem total de micro-organismos e micro-organismos patógenos devem ser estabelecidos previamente e realizados em cada lote.

Após a realização do controle de qualidade, devem ser emitidos certificados de análise para cada lote expedido de IFA. No certificado de análise devem constar no mínimo: nome do IFA utilizando nomenclaturas DCB, DCI ou CAS (quando possível), número de lote, data de fabricação e data de validade. Cada teste executado incluindo os limites de aceitação e os resultados obtidos, e referências da metodologia analítica utilizada, data da emissão do certificado, identificação e assinatura por pessoa autorizada da unidade da qualidade e identificação do fabricante.

O próximo passo é a embalagem e rotulagem. Os materiais de acondicionamento não devem interferir na qualidade do IFA e precisam assegurar proteção e estabilidade do produto. No que se refere à rotulagem, o Art. $191^{\circ}$ determina que as embalagens devem estar claramente identificadas com as seguintes informações: nome do produto (DCB, DCl ou CAS, quando possível), número do lote, data de validade ou de reteste e data de fabricação, quantidade e sua respectiva unidade de medida, advertências (se necessárias), condições de armazenamento, nome, identificação e endereço do fabricante, nome do responsável técnico e inscrição no Conselho de classe, e outros requisitos conforme a categoria do IFA, de acordo com a legislação vigente. Subsequente à rotulagem, o produto 
somente poderá ser expedido após a liberação do responsável pela qualidade.

Estudos de Estabilidade devem ser realizados dee acordo com o Art. $292^{\circ}$, que determina que deva ser implantado um programa documentado para monitoramento, com indicação dos métodos analíticos a serem empregados. Os métodos analíticos utilizados no estudo de estabilidade devem ser validados e são usados como indicadores de estabilidade. As amostras devem ser acondicionadas em recipientes com a mesma composição química e características físicas da embalagem de comercialização como relata o Art. $294^{\circ}$. No Art. $295^{\circ}$ é relatado que esses estudos devem ser realizados com, no mínimo, três lotes de IFA, e as condições climáticas devem ser estabelecidas para este ensaio.

Após a produção dos IFAs e garantia de suas qualidade e estabilidade, dá-se início à produção do medicamento, que passa a seguir as exigências da RDC nํ17/10 (ANVISA), que define as BPFs de produção de medicamento empregadas pela indústria farmacêutica (BRASIL, 2010).

Desta forma, para que um IFA seja produzido por uma indústria, deve-se obedecer a critérios mínimos de qualidade determinados pela ANVISA, desde a sua obtenção até sua expedição final, garantindo dessa forma, a qualidade e integridade do produto em questão, bem como a saúde da população.

\section{CONCLUSÃO}

No presente estudo pode-se observar a importância que as legislações têm nos processos de produção dos insumos farmacêuticos ativos. Tais regulamentações estabelecidas pela ANVISA servem para garantir ao máximo a qualidade dos insumos que posteriormente serão transformados em medicamentos e consumidos pela população. Essas regulamentações envolvem desde o registro do insumo, produção, controle de qualidade na produção, expedição e comprovação da qualidade do produto acabado. No caso específico da heparina, a legislação empregada desempenha um papel de extrema importância, já que essa vai determinar a qualidade e o rendimento do produto final. Contudo, vale ressaltar que esse é um tema pouco explorado no meio acadêmico e científico o que ficou evidenciado durante a pesquisa em relação a disponibilidade de material científico sobre os assuntos regulatórios. Desta forma, é um campo que merece atenção e incentivo por parte do ambiente acadêmico, permitindo uma maior elucidação das legislações publicadas pela ANVISA. 


\section{REFERÊNCIAS}

Anvisa. Agência Nacional de Vigilância Sanitária. Insumos farmacêuticos. Rev. Saúde Pública. v. 40, n. 2, p. 359-360, 2006.

Aquino RS, et al. Heparins from porcine and bovine intestinal mucosa: Are they similar drugs? Thromb. Haemost. v. 103, n. 5, p.1005- 1015, 2010.

Arrepia DB, Costa JCS, Tabak D. Registro de insumos farmacêuticos ativos: impactos e reflexos sobre as indústrias farmoquímica e farmacêutica instaladas no Brasil. VISA em Debate. v. 3, n. 2, p.9-19, 2015.

Barrowcliffe, TW. History of Heparin. Handb Exp. Pharmacol. v.207, p. 3-22, 2012.

Boneu B. Low Molecular Weight Heparins: Are They Superior to Unfractionated Heparins to Prevent and to Treat Deep Vein Thrombosis? Thromb. Res. v. 100, n. 2, p. V113-V120, 2000.

Brasil. Decreto ํo 74.170 de 10 de junho de 1974. Regulamenta a Lei n.ํ‥991, de 17 de dezembro de 1973, que dispõe sobre o controle sanitário do comércio de drogas, medicamentos, insumos farmacêuticos e correlatos. Diário Oficial da União. 11 jun 1974.

Brasil. Insumos Farmacêuticos. Agência Nacional de Vigilância Sanitária (ANVISA). [Acesso em: 24 ago. 2015]. Disponível em: <http://portal.anvisa.gov.br/wps/content/Anvisa +Portal/Anvisa/Inicio/Insumos+Farmaceuticos>

Brasil. Lei o 5.991 de 17 de dezembro de 1973. Dispõe sobre o controle sanitário do comércio de drogas, medicamentos, insumos farmacêuticos e correlatos, e dá outras providências. Diário Oficial da União. 19 dez 1973.

Brasil. Resolução de Diretoria Colegiada n 29 de 10 de agosto de 2010. Dispõe sobre certificação de Boas Práticas de Fabricação para fabricantes internacionais de insumos farmacêuticos ativos. Diário Oficial da União. 12 ago 2010.

Brasil. Resolução de Diretoria Colegiada n 69 de 8 de dezembro de 2014. Dispõe sobre 
as Boas Práticas de Fabricação de insumos farmacêuticos ativos. Diário Oficial da União. 9 dez 2014.

Brasil. Resolução de Diretoria colegiada ํo 17 de 16 de abril de 2010. Dispõe sobre boas práticas de fabricação de medicamentos. [Acesso em: 17/01/2018]. Disponível em:http://portal.anvisa.gov.br/documents/33880/2568070/res0017_16_04_2010.pdf/b9a8a 293-f04c-45d1-ad4c-19e3e8bee9fa

Brasil. Resolução de Diretoria Colegiada no 39 de 14 de agosto de 2013. Dispõe sobre os procedimentos administrativos para concessão da Certificação de Boas Práticas de Fabricação e da Certificação de Boas Práticas de Distribuição e/ou Armazenagem. Diário Oficial da União. 14 ago 2013.

Brasil. Resolução de Diretoria Colegiada ํo 55 de 16 de dezembro de 2010. Dispõe sobre o registro de produtos biológicos novos e produtos biológicos e dá outras providências. Diário Oficial da União. 17 dez 2010.

Delucia, R et.al. Farmacologia Integrada. Rio de Janeiro: Revinter, 2007.

Filho, NA. Desafios na qualidade de heparinas. Rev. Bras. Hematol. Hemoter. v. 31, n. 5, p. 306-307, 2009.

Gonçalves GF. Análise das estratégias competitivas da indústria farmacêutica brasileira segundo a tipologia de Chrisman. [Dissertação] Rio de Janeiro: Departamento de Administração, 2006.

Guerrini M, Beccati D, Shriver Z, Naggi A, Viswanathan K, Bisio A, et al. Oversulfated chondroitin sulfate is a contaminant in heparin associated with adverse clinical events. Nat. Biotechnol. v. 26, n. 6, p. 669-675, 2008.

Liverani L, Mascellani G, Spelta F. Heparins: process-related physico-chemical and compositional characteristics, fingerprints and impurities. Thromb. Haemost. v. 102, n. 5, p. 846-853, 2009. 
Longhi F, Laks D, Kalil NGN. Trombocitopenia induzida por heparina. Rev. Bras. Hematol. Hemoter. v. 23, n. 2, p.103-110, 2001.

Lopes ALM, Fracolli LA. Revisão sistemática de literatura e metassintese qualitativa: Considerações sobre sua aplicação na pesquisa em enfermagem. Texto Contexto Enferm. v.17, n. 4, p. 771-778, 2008.

Mastroianni PC, Lucchetta RC. Regulamentação Sanitária de Medicamentos. Rev. Ciênc. Farm. Básica Apl. v. 32, n. 1, p. 127-132, 2011.

Masuko S, Linhardt RJ. Chemoenzymatic synthesis of the next generation of ultralow MW heparin therapeutics. Future Med. Chem. v. 4, n. 3, p. 289-96, 2012. doi: 10.4155/fmc.11.185.

Mauro MFZ, Wang R, Cristovãos AB, Salman AA, Oliveira JB, Mangione JA. Novos Inibidores da Trombina: Qual o Estado Atual das Pesquisas? Rev. Bras. Cardiol. Invasiva. v. 12, n. 3, p. 130-137, 2004.

Melo, El et al. Controle da qualidade das preparações de heparina disponíveis no Brasil: implicações na cirurgia cardiovascular. Rev. Bras. Cir. Cardiovasc. v. 23, n. 2, p. 169-174, 2008.

Messmore HL, Wehrmacher WH, Coyne E, Fareed J. Heparin to pentasaccharide and beyond: the end is not in sight. Semin. Thromb. Hemost. v. 30, n. Suppl 1, p. 81-88, 2004.

Mitidieri TL, Pimentel VP, Braga CA, Pieroni, JP. Há espaços competitivos para a indústria farmoquímica brasileira? Reflexões e propostas para políticas públicas - Complexo Industrial da Saúde - BNDES Setorial.v.41, p.1-36, 2015.

Mulloy B, Hogwood J, Gray E, Lever R, Page CP. Pharmacology of Heparin and Related Drugs. Pharmacol. Rev. v. 68, n. 1, p. 76-141, 2016.

Paula PAB, Alves TNP, Vieira RCPA, Souza AIS. Política de medicamentos: da universalidade de direitos aos limites da operacionalidade. Physis. v. 19, n. 4, p. 11111125, 2009. 
Pontes AT, Xavier LS, Futuro DO, Peixoto JAA. Uma reflexão da qualidade dos insumos farmacêuticos presentes no marcado brasileiro e seu impacto na produção de medicamentos. In: Anais do XXIX Encontro Nacional de Engenharia da Produção - A Engenharia de Produção e o Desenvolvimento Sustentável: Integrando Tecnologia e Gestão; 2009; Salvador, p. 1-12.

Rang HP, et al. Farmacologia. Rio de Janeiro: Elsevier, 2011.

Santos GR, Tovar AM, Capillé NV, Pereira MS, Pomin VH, Mourão PA. Structural and functional analyses of bovine and porcine intestinal heparins con-firm they are different drugs. Drug Discov. Today. v. 19, n. 11, p. $1801-1807,2014$.

Tovar AM, Teixeira LA, Rembold SM, Leite M Jr, Lugon JR, Mourão PA. Bovine and porcine heparins: different drugs with similar effects on human haemodialysis. BMC Res. Notes. v. 6, n. 230, p. 1-8, 2013.

Walenga JM, Lyman GH. Evolution of heparin anticoagulants to ultra-low-molecular-weight heparins: A review of pharmacologic and clinical differences and applications in patients with câncer. Crit. Rev. Oncol. Hematol. v. 88, n. 1, p. 1-18, 2013. 